
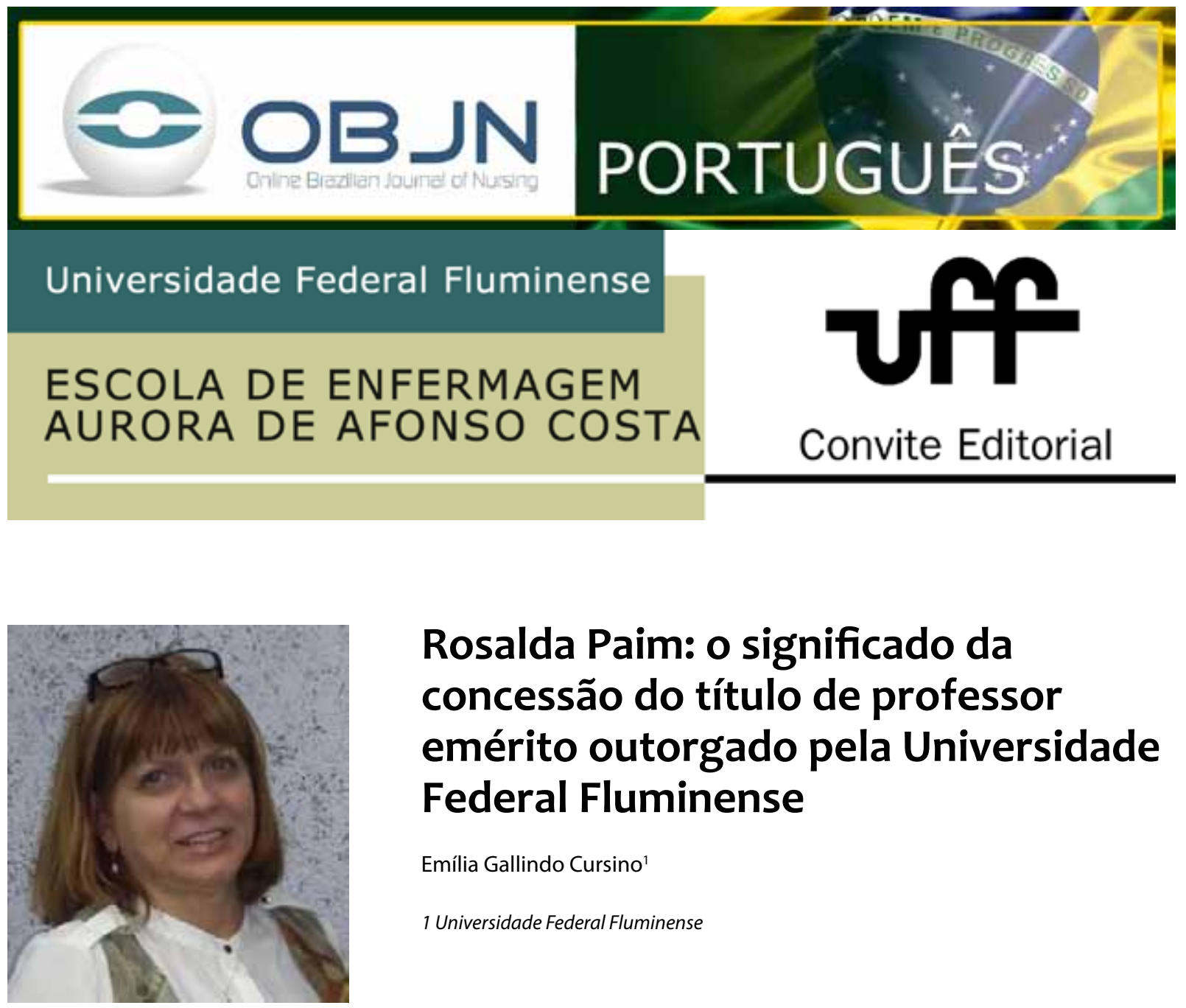

\title{
Rosalda Paim: o significado da concessão do título de professor emérito outorgado pela Universidade Federal Fluminense
}

Emília Gallindo Cursino

1 Universidade Federal Fluminense

\section{RESUMO}

É delicada a tarefa de selecionar e condensar, em poucas páginas, os aspectos de maior relevo da vida e obra desta ilustre professora, quando se tem a noção muito clara de que todos eles foram igualmente significativos, cada um a seu modo, para consolidar tão singular trajetória no cenário acadêmico. Este editorial resgata parte do discurso proferido durante a homenagem de Professor Emérito à Profa. Dra. Rosalda Cruz Nogueira Paim, conferido pela Universidade Federal Fluminense. O texto objetiva, em forma de narrativa, cujas informações foram geradas a partir de referências impressas e online publicadas, registrar uma acanhada amostra da grande contribuição dada pela Profa. Rosalda Paim à vida da EEAAC/UFF e às vidas de todos que tiveram o privilégio de com ela conviver.

Descritores: História; Memória; Enfermagem. 


\section{INTRODUÇÃO}

Emérito, do latim emeritus, significa merecer $^{1}$. Professor emérito é um título honorífico conferido aos professores ilustres, de grande competência, com grande conhecimento em determinada área. $\mathrm{O}$ título de Professor Emérito da Universidade Federal Fluminense (UFF) é concedido aos docentes da instituição que se destacaram no exercício da atividade acadêmica, caso da professora Rosalda Paim. A cerimônia de outorga do título foi realizada no dia 17 de maio de 2016, no auditório "Dra. Rosalda Paim" da Escola de Enfermagem Aurora de Afonso Costa (EEAAC).

Para esta escola, o título de professora emérita outorgada à professora Rosalda Paim, tem um significado especial, considerando sua notável trajetória.

O passado e o futuro são dois polos que o presente materializa e une. Assim foi a magistral vida desta ilustre professora, cujo passado se exemplificou nos atos e atitudes bondosas, generosas, amigas e fraternas com que ela sempre distinguiu seus superiores, colegas, estudantes e pacientes. O seu futuro, com certeza, foi o resultado e o somatório de tudo quanto fez na formação do enfermeiro e de profissionais de saúde, na mudança de paradigma da atenção em saúde e, sobretudo, no processo de modernização da enfermagem brasileira.

Rosalda Paim, ícone da enfermagem brasileira pelo seu relevante papel na construção do campo científico, por seu compromisso com a saúde e a educação, e por sua representação política. Este editorial discorrerá sobre a história de uma mulher que além de enfermeira, pedagoga, pesquisadora e deputada, foi uma personalidade visionária, militante política, defensora da saúde pública e dos cuidados de enfermagem nos diferentes ciclos da vida².

\section{QUEM FOI ROSALDA PAIM}

Mulher dedicada à família, humana, sensível, espirituosa e generosa, mostrou-se sempre firme em suas convicções e posições.

Nossa homenageada é capixaba, nasceu em Vila Velha, no estado do Espírito Santo, em 26 de agosto de 1928, filha de Valeriano Rodrigues da Cruz e Lindaura Evangelista da Cruz. Faleceu em 02 de junho de 2015, na cidade do Rio de Janeiro.

Casou-se com Edson Paim, cirurgião dentista, médico, professor aposentado da UFF, parceiro de militância política, de produção teórica, além de um grande companheiro que a acompanhou por mais de 60 anos. Com ele teve cinco filhos, os quais lhe deram 12 netos e um bisneto.

\section{TRAJETÓRIA ACADÊMICA - 1950/1997}

\section{O início}

Rosalda Paim graduou-se em Enfermagem pela Escola de Enfermagem do Estado do Rio de Janeiro, atualmente denominada Escola de Enfermagem Aurora de Afonso Costa (EEAAC/ UFF) (1947-1950). Concluiu o curso de Bacharel em Pedagogia (1953-1956) e licenciou-se no mesmo curso pelo Instituto de Filosofia e Ciências Humanas da UFF em 1957.

Especializou-se nas áreas de Pediatria, Administração Hospitalar e Saúde Pública. Realizou mestrado em Educação na Faculdade de Educação da UFF e doutorou-se em 1975 em Enfermagem Materno-Infantil, defendendo tese de livre docência pela Pontifícia Universidade Católica do Rio de Janeiro.

Na Escola de Enfermagem do Estado do Rio de Janeiro, Rosalda Paim foi instrutora de ensino 
entre 1950 e 1952. Em 1958 foi responsável pela Divisão de Ensino; e, em 1967, foi contratada como auxiliar de ensino na cadeira de Fundamentos de Enfermagem.

No ensino, desenvolveu atividades em várias disciplinas de graduação e pós-graduação lato sensu e stricto sensu, destacando-se as áreas de Materno-Infantil, Saúde Pública e de Metodologia da Pesquisa. Foi professora de: Prática de Ensino, Didática Aplicada à Enfermagem, Enfermagem Pediátrica, Enfermagem Materno- Infantil. Foi professora titular de pesquisa, a partir de 1978, e orientadora de pesquisas e monografias até 1999.

Efeitos de sua atuação como Professora Titular de Pesquisa

Mediante concurso público de provas e títulos, foi nomeada Professora Titular do Departamento de Enfermagem Materno-Infantil e Psiquiatria da EEAAC/UFF, onde ocupou o cargo de chefia de departamento no período 1990-1992. Ainda na década de 1990, compôs um grupo de docentes que iniciou discussões para a criação de um curso de mestrado na EEAAC/UFF. Como efeitos desta sua atuação, em 2005 deu-se a criação do Mestrado Profissional em Enfermagem Assistencial (MPEA), sendo coordenadora de honra e professora emérita; e, em 2008, a criação do Mestrado Acadêmico em Ciências do Cuidado em Saúde (MACCS) ${ }^{3}$.

Foi líder do Grupo de Pesquisa "CNPq" (Catálogo 1992/93/94/05 e 96 a 98); exerceu intensa atividade de orientação de monografias de conclusão de cursos de aperfeiçoamento, especialização e de iniciação científica. Presidiu e integrou bancas de exame de teses de livre docência, de cursos de mestrado e doutorado em diversas faculdades de enfermagem do estado do Rio de Janeiro e do país ${ }^{3}$.
Como doutora na área materno-infantil, teorizou sobre a infância como uma fase do desenvolvimento humano que precisa ser considerada um fenômeno em si, de direito da criança e não apenas como uma fase transitória².

A visão ampla na produção de conhecimento de pesquisa na saúde e na enfermagem está expressa em suas obras. O trabalho de Paim propagou-se para além da enfermagem, na educação, na ecologia, no planejamento em saúde e na assistência social.

\section{Na Pesquisa-Publicações}

No âmbito da pesquisa, elaborou, em 1974, a Teoria Sistêmica Ecológica Cibernética de Enfermagem, objeto de sua tese de livre-docência, e também publicada nos livros, de sua autoria, "Metodologia Científica de Enfermagem" e "Um paradigma para a Enfermagem". Entre outras publicações, destaca-se o "Sistemismo Ecológico Cibernético". O conjunto da sua obra trata do sistemismo, da ecologia e da cibernética, denominados atualmente de cuidado essencial, ecológico e complexo².

Rosalda Paim contribuiu teoricamente para o avanço de conceitos pós-modernos aplicados à saúde e à enfermagem quando ainda predominava o paradigma curativista, centrado no modelo biomédico, desconsiderando as possíveis relações entre o homem e o meio. Sua produção científica é fértil, composta por livros escritos, por vários artigos publicados em revistas, apresentados e publicados em anais de congressos e conferências nacionais e internacionais.

\section{Na Extensão Universitária}

Em sua marcante atuação na extensão universitária, destacam-se: o Programa Integrado de Saúde Materno-Infantil (PISMI) - a sala 149 (HUAP) e o Programa Docente Assistencial 
na Área da Saúde (PIDAS), que tiveram como propósito a extensão de cobertura à saúde da população de Niterói, em uma linha de hierarquização dos serviços de saúde local, e desencadear e manter o processo de ação integrada, docente-assistencial, dos vários profissionais atuantes na área; a criação do Núcleo de Atenção Primária à Educação e Saúde (NAPES); e a criação da Creche Comunitária Rosalda Paim.

Ainda no contexto da extensão, sublinha-se a implantação da Triagem Geral do Hospital Universitário Antônio Pedro (HUAP), sistema de referência e contrarreferência resultante dos projetos "PISMI" e "PIDAS. Tais feitos antecederam as dimensões do princípio de integralidade do Sistema Único de Saúde (SUS), proposto na lei infraconstitucional de $n^{\circ} 8.080 / 90^{4}$.

Rosalda Paim foi presidente da Associação Brasileira de Enfermagem (ABEn) de Niterói, na qual também ocupou a coordenação da Comissão de Educação entre agosto de 1976 e junho de 1980.

Suas atividades de extensão sempre estiveram imbricadas com o ensino e a pesquisa, de modo que Rosalda Paim teve um papel notório na formação de enfermeiros e de outros profissionais de saúde, na mudança de paradigma na atenção em saúde e, no processo de modernização da enfermagem brasileira.

\section{Na Vida Parlamentar - Militância Política}

Rosalda Paim teve expressão política significativa como a "Primeira Enfermeira Parlamentar" do Brasil, exercendo o mandato no período de 1983 a 1987. É autora de mais de vinte leis voltadas para a área de saúde e social, dentre as quais: a que proíbe a coleta remunerada de sangue; a de criação do sistema estadual de creche; da criação do dia da pessoa idosa; da criação do serviço de saúde do adolescente; e a da obrigatoriedade de instalação de conselhos comunitários em unidades estaduais de saúde, educação e serviço social.

Neste período, presidiu a Comissão de Saúde, a de Educação e outras da Assembleia Legislativa do estado do Rio de Janeiro.

\section{O Reconhecimento Profissional}

Dentre as homenagens recebidas por Rosalda Paim, ao longo de sua vida acadêmica, citam-se:

1. Título de Professor Emérito da Universidade Federal Fluminense;

2. Inclusão no rol de Cientistas Brasileiros, pela UFF;

3. Título de "Primeira Enfermeira Parlamentar do Brasil";

4. Título de cidadã do estado do Rio de Janeiro, atribuído pela Assembleia Legislativa;

5. Instituição da Semana de Estudos e Pesquisas Rosalda Paim, da EEAAC/UFF;

6. Denominação de Creche Comunitária Rosalda Paim a uma Unidade Municipal de Ensino Infantil da prefeitura de Niterói/RJ;

7. Denominação de "Anfiteatro Dra. Rosalda Paim", nome dado ao auditório principal da EEAAC/UFF;

8. Denominação de "Estádio Esportivo Rosalda Paim (ROSALDÃO)", atribuída pelo câmara municipal de Anastácio/MS;

9. Título de professor emérito outorgado pela Fundação Educacional Serra dos Órgãos (FESO), Teresópolis/RJ;

10. Patrona, Paraninfa e nome de várias turmas de formandos de faculdades de enfermagem em Niterói, e situadas no Rio de Janeiro, Teresópolis, Duque de Caxias e Volta Redonda;

11. Título de cidadã dos municípios fluminenses de Duque de Caxias, Niterói e de Italva; e de Anastácio, no Mato Grosso do Sul, atribuídos pelas respectivas câmeras de vereadores. 


\section{O melhor da Profa. Rosalda Paim}

O melhor da professora Rosalda não foi sua capacidade acadêmica e sua inteligência, mas sim a pessoa humana que ela foi. Quem teve a oportunidade de contar com a sua amizade e o seu companheirismo é um iluminado e pode atestar o que aqui foi narrado. Tomara que estas poucas páginas sejam suficientes para dar uma acanhada manifestação da grande contribuição dada pela professora à vida da EEAAC/UFF, à enfermagem brasileira e às vidas de todos que tiveram o privilégio de com ela conviver.

\section{REFERÊNCIAS}

1. Ferreira $A B H$. Novo Dicionário Aurélio da Língua Portuguesa. 3 ed. Curitiba: Positivo; 2004

2. Teixeira ER, Daher DV, Santana RF, Fonseca TC. Rosalda Paim: a nurse beyond her time. Online braz j nurs [internet]. 2012 Aug [cited 2016 Jun 3]; 11(2): 408- 17. Available from: http://www. objnursing.uff.br/index.php/nursing/article/ view/3967 408

3. Universidade Federal Fluminense. Memorial interativo Rosalda Paim [homepage] Niterói; 2011. [cited 2012 Sept 3]. Available from: www. rosaldapaim.uff.br

4. Brasil. Presidência da República, Subchefia para Assuntos Jurídicos. Lei $n^{\circ}$ 8.080. Dispõe sobre as condições para a promoção, proteção e recuperação da saúde, a organização e funcionamento dos serviços correspondentes e dá outras providencias. [internet] Brasília, DF; 1990. [cited 2016 Jun 2]. Available from: http://www.planalto.gov. br//ccivil03/Leis/L8080.htm.
Todos os autores participaram das fases dessa publicação em uma ou mais etapas a seguir, de acordo com as recomendações do International Committe of Medical Journal Editors (ICMJE, 2013): (a) participação substancial na concepção ou confecção do manuscrito ou da coleta, análise ou interpretação dos dados; (b) elaboração do trabalho ou realização de revisão crítica do conteúdo intelectual; (c) aprovação da versão submetida. Todos os autores declaram para os devidos fins que são de suas responsabilidades o conteúdo relacionado a todos os aspectos do manuscrito submetido ao OBJN. Garantem que as questões relacionadas com a exatidão ou integridade de qualquer parte do artigo foram devidamente investigadas e resolvidas. Eximindo, portanto o OBJN de qualquer participação solidária em eventuais imbróglios sobre a materia em apreço. Todos os autores declaram que não possuem conflito de interesses, seja de ordem financeira ou de relacionamento, que influencie a redação e/ou interpretação dos achados. Essa declaração foi assinada digitalmente por todos os autores conforme recomendação do ICMJE, cujo modelo está disponível em http://www. objnursing.uff.br/normas/DUDE_final_13-06-2013.pdf

Recebido: $15 / 06 / 2016$

Aprovado: 29/06/2016 